\title{
Aktivitas Antijamur Ekstrak Teh Putih (Camelia sinensis) terhadap Jamur Candida Albicans (Antifungal Activity of White Tea Extract to Candida albicans)
}

\author{
Asri Widyasanti ${ }^{1)}$, David S.S Marpaung ${ }^{2)}$ dan Sarifah Nurjanah ${ }^{1)}$ \\ ${ }^{1)}$ Dosen Departemen Teknik Pertanian dan Biosistem, FTIP,Universitas Padjadjaran \\ ${ }^{1)}$ Alumni Departemen Teknik Pertanian dan Biosistem, FTIP,Universitas Padjadjaran \\ Jl. Raya Bandung Sumedang KM 21, Jatinangor Bandung 40600 \\ Email : asriwidyasanti@gmail.com
}

\begin{abstract}
ABSTRAK
Teh putih merupakan jenis teh yang masih terdengar asing, terutama apabila dibandingkan dengan popularitas teh hitam dan teh hijau. Hal tersebut mendasari perlunya dilakukan penggalian potensi teh putih agar dapat dimanfaatkan menjadi produk olahan selain minuman di Indonesia. Penelitian ini bertujuan untuk menguji potensi antijamur dari ekstrak teh putih terhadap jamur Candida albicans. Teh putih didapatkan di Pusat Penelitian Teh dan Kina, Gambung, Ciwidey, Jawa Barat. Metode yang digunakan pada penelitian ini adalah eksperimental dengan analisis deksriptif. Uji potensi antijamur ekstrak teh putih dilakukan dengan metode difusi agar pada medium Potatos Dexstrose Agar (PDA) dengan menggunakan paper disc. Setiap paper disc direndam pada ekstrak teh putih dengan konsentrasi $22 \%, 24 \%, 26 \%$ dan $28 \%(\mathrm{~b} / \mathrm{v})$. Diameter daya hambat yang dihasilkan pada ekstrak teh putih pelarut $n$-heksana adalah sebesar 0,83-2,83 mm, ekstrak teh putih dengan pelarut etil asetat adalah $6,16-11,33 \mathrm{~mm}$, sedangkan pada ekstrak teh putih dengan pelarut etanol $96 \%$ adalah $10,00-16,16$ $\mathrm{mm}$. Hasil penelitian menunjukkan bahwa ekstrak teh putih dengan pelarut etanol memiliki daya hambat terbaik sebesar $16,16 \mathrm{~mm}$ pada konsentrasi $28 \%(\mathrm{~b} / \mathrm{v})$. Konsentrasi hambat minimum yang diuji menggunakan ekstrak teh putih dengan pelarut $n$-heksana tidak ditemukan, ekstrak teh putih pelarut etil asetat ditemukan pada konsentrasi $22 \%(\mathrm{~b} / \mathrm{v})$ sebesar $11,33 \mathrm{~mm}$ dan pada ekstrak teh putih dengan pelarut etanol $96 \%$ ditemukan pada konsentrasi $22 \%(\mathrm{~b} / \mathrm{v})$ sebesar $11,50 \mathrm{~mm}$.
\end{abstract}

Kata kunci: Aktivitas Antijamur, Candida albicans, Ekstrak Teh Putih.

\begin{abstract}
White tea is the type of tea that rarely heard, especially when it compared to the popularity of black tea and green tea. It is necessary to explore the potency of white tea so that it can be utilized as processed products besides for beverages products in Indonesia. This study aimed to examine the antifungal activity of white tea extract against Candida albicans fungi. White tea pekoe was obtained from Research Center of Tea and Quinine, Gambung, Ciwidey, West Java. The method used in this research was experimental laboratory with descriptive analysis. Antifungal activity method that used was agar diffusion method in medium Potatos Dexstrose Agar (PDA) using paper discs that were soaked with white tea extract. Each paper disc soaked in white tea extract with several concentrations such as $22 \%, 24 \%, 26 \%$ and $28 \%(\mathrm{w} / \mathrm{v})$, respectively. The results of inhibition diameter of white tea extract with $n$-hexane solvents were $0.83-2.83 \mathrm{~mm}$. While inhibition diameter of white tea extract with ethyl acetate solvents were 6.16 - $11.33 \mathrm{~mm}$, then inhibition diameter of white tea extract with ethanol 96\% solvents were $10.00 \mathrm{~mm}-16.16 \mathrm{~mm}$. The results showed that white tea extract with ethanol $96 \%$ solvents was the best inhibition diameters with $16.16 \mathrm{~mm}$ at a concentration of $28 \%(\mathrm{w} / \mathrm{v})$. The minimum inhibitory concentrations (MIC) were tested using white tea extract with n-hexane solvents was not found, while MIC of white tea extract with ethyl acetate solvents was found at concentration of $22 \%(\mathrm{w} / \mathrm{v})$ with $11.33 \mathrm{~mm}$ in diameter, and MIC white tea extract with ethanol $96 \%$ solvents was found in $22 \%$ concentration with $11.50 \mathrm{~mm}$ in diameter.
\end{abstract}

Keywords: Antifungal Activity, Candida albicans, White Tea Extract.

Diterima : 16 Juli 2016 ; Disetujui : 13 Oktober 2016 


\section{PENDAHULUAN}

Teh putih adalah teh yang memiliki bulubulu halus berwarna putih. Selain itu teh putih merupakan teh yang olahan dan jenisnya paling sedikit di dunia. Menurut Balai Penelitian Tanaman Industri (2013), teh putih merupakan jenis teh yang masih terdengar asing terutama apabila dibandingkan dengan popularitas teh hitam dan teh hijau. Hal tersebut disebabkan karena jenis teh tersebut merupakan jenis teh yang paling langka di dunia dan untuk mendapatkannya, harus mengambil dari satu pucuk tiap satu pohon, yakni pucuk tertinggi dan utama sehingga jumlah yang diproduksi relatif sedikit.

Komposisi senyawa kimia daun teh secara umum terdiri atas 4 kelompok besar, yaitu substansi fenol, substansi bukan fenol, substansi aromatik dan enzim (Syah, 2006). Salah satu bagian dari substansi fenol adalah flavonoid. Berdasarkan strukturnya, flavanoid terdiri dari 6 kelas, yaitu flavone, flavaonone, isoflavone, flavonol, flavanol dan antosianin. Adapaun flavanoid yang sering ditemukan pada teh berupa flavanol dan flavonol (Hartoyo, 2003). Manfaat utama teh berasal dari senyawa flavanol yang dikandungnya. Senyawa-senyawa yang terdapat pada flavanol di teh terdiri dari senyawa epikatekin (EC), epikatekin galat (ECG), epigalokatekin (EGC), epigalokatekin galat (EGCG), katekin (C) dan galokatekin (GC) (Chu dan Juneja, 1997). Menurut Basson dkk. (1996), salah satu senyawa utama yang dikandung teh putih adalah Katekin. Katekin pada teh memiliki sifat larut dalam air, membawa sifat pahit pada seduhan teh serta tidak memiliki warna. Pelczar dan Chan (2005), menjelaskan bahwa substansi fenol merupakan kelompok utama bahan antimikrobial kimiawi.

Ekstraksi merupakan proses penarikan komponen aktif menggunakan pelarut tertentu. Komponen aktif yang diambil adalah senyawa aktif dalam teh putih. Secara umum ekstraksi senyawa metabolit sekunder dari seluruh bagian tumbuhan seperti bunga, buah, daun, kulit batang dan akar dilakukan maserasi. Menurut Darwis (2000), maserasi merupakan proses perendaman sampel dengan pelarut organik yang digunakan pada temperatur ruangan. Proses ini sangat menguntungkan dalam ekstraksi senyawa bahan alam karena dengan perendaman sampel tumbuhan akan terjadi pemecahan dinding dan membran sel akibat perbedaan tekanan antara di dalam dan di luar sel sehingga metabolit sekunder yang ada dalam sitoplasma akan terlarut dalam pelarut organik dan ekstraksi senyawa akan sempurna karena dapat diatur lama perendaman yang dilakukan. Maserasi dapat dimodifikasi menjadi beberapa metode, salah satunya yaitu maserasi bertingkat. Pada maserasi bertingkat, ampas yang telah dimaserasi dapat dimaserasi kembali dengan pelarut yang berbeda.Ekstraksi dilakukan secara bertingkat, dimana urutan ekstraksi ditentukan berdasarkan tingkat kepolaran pelarut. Pemilihan jenis didasarkan pada sifat kelarutan zat yang mengikuti pada teori like disolve like, yaitu zat yang bersifat polar akan larut dalam pelarut polar dan zat yang bersifat nonpolar akan larut dalam pelarut nonpolar (Khopkar, 2003).

Jamur merupakan salah satu penyebab penyakit kulit di negara-negara yang beriklim tropis. Hal ini disebabkan karena iklim tropis memiliki kelembaban udara yang tinggi sehingga mendukung pertumbuhan jamur.Indonesia merupakan salah satu negara yang beriklim tropis. Indonesia merupakan negara yang rentan terkena penyakit kulit yang disebabkan oleh jamur. Candida spp dikenal sebagai jamur dimorfik yang secara normal ada pada saluran pencernaan, saluran pernafasan bagian atas dan mukosa genital pada mamalia tetapi populasi yang meningkat dapat menimbulkan masalah.Jamur Candida albicans dianggap menjadi penyebab utama kandidiasis. Candida albicans merupakan jamur opportunistik penyebab sariawan, lesi pada kulit, vulvavaginistis, candida pada urin (kandiduria), gastrointestinal kandidiasis yang dapat menyebabkan gastric ulcer, atau bahkan dapat menjadi komplikasi kanker (Kurniawan, 2009).

Salah satu jenis teh, yaitu teh hijau dapat menghambat pertumbuhan jamur penyebab penyakit kulit Candida albicans dengan kadar bunuh minimum yang ditemukan pada ekstrak teh hijau konsentrasi 35\% (Prasidha, 2013). Menurut Pastore (2005) ekstrak teh putih mempunyai efek menghambat pertumbuhan jamur Penicillium chrysogenum dan Saccharomyces cerevisiae. Berdasarkan hal tersebut, teh putih diduga dapat menghambat pertumbuhan jamur Candida albicans. Penelitian ini bertujuan untuk 
mengetahui aktivitas antijamur dari ekstrak teh putih terhadap jamur Candida albicans.

\section{METODOLOGI PENELITIAN}

\section{Alat dan Bahan}

Bahan yang digunakan antara lain teh putih yang berasal dari Pusat Penelitian Teh dan Kina Gambung, Bandung. Bahan kimia yang digunakan adalah etanol 96\%, n-heksana, etil asetat,etanol 95 $\%$, etanol $70 \%$, asam galat, $\mathrm{NaCl} 0,85 \%$ (b/v), $\mathrm{BaCl} 2$ $1 \%(b / v), \mathrm{H} 2 \mathrm{SO} 41 \%(b / v), \mathrm{Na} 2 \mathrm{CO} 3 \%$, reagen Folin Ciocalteau, supernatan dan $\mathrm{NaOH}$. Uji antijamur menggunakan biakan murni jamur Candida albicans yang berasal dari Laboraturium Mikrobiologi Fakultas Farmasi Universitas Padjadjaran, akuades steril, spiritus, Potato Dextrose Agar (PDA)

Alat-alat yang digunakan autoklaf, cawan alumunium, cawan petri, corong buchner, cuvet, desikator, gelas ukur, grinder, hot plate stirrer, inkubator, jarum ose, magnetic stirrer, mikropipet, oven, piknometer, rotap tyler sieves, rotary vacuum evaporator merk Heidolph model RX-2910, chromameter merk Konika Minolta, thermohygrometer digital merk Lutron HT-3015, timbangan analitik merk Boeco, Germany dan vortex mixer tipe VM-300.

\section{Metode Penelitian}

Metode penelitian yang digunakan adalah metode eksperimental laboratorium dengan analisis deskriptif sehingga diharapkan dapat memberikan informasi tentang antijamur dari ekstrak teh putih terhadap pertumbuhan jamur Candida albicans. Pada penelitian ini diamati aktivitas antijamur pada ekstrak teh putih yaitu berupa diameter daya hambat. Pelarut yang digunakan adalah pelarut $\mathrm{n}$-heksana (bersifat nonpolar), etil asetat (bersifat semipolar) dan etanol 96\% (bersifat polar). Konsentrasi yang digunakan pada tiap jenis pelarutnya adalah $22 \%(\mathrm{~b} / \mathrm{v}), 24 \%$ $(b / v), \quad 26 \% \quad(b / v)$ dan 28\% (b/v). Pemilihan konsentrasi ekstrak berdasarkan hasil penelitian pendahuluan yang menunjukan bahwa pada ekstrak teh putih pelarut etanol konsentrasi $30 \%$ memiliki daya hambat terbesar yaitu $13,60 \mathrm{~mm}$ sehingga perlu dilakukan pengujian pada konsentrasi yang lebih kecil dari 30\% untuk mengetahui konsentrasi hambat minimum. Kontrol yang digunakan adalah ketoconazole. Hal ini dikarenakan ketoconazole merupakan antijamur komersial yang dapat menghambat pertumbuhan jamur Candida albicans. Parameter pendukung yang diamati, yaitu nilai kadar air, nilai rendemen, nilai kadar sisa pelarut, nilai bobot jenis, warna dan kandungan polifenol ekstrak teh putih. Hal ini perlu dilakukan untuk mengetahui faktor-faktor yang mempengaruhi aktivitas antijamur ekstrak teh putih terhadap jamur Candida albicans.

Penelitian ini terdiri dari tiga tahapan, yaitu tahapan persiapan bahan pembuatan ekstrak teh putih, dan pengukuran diameter daya hambat (pengujian aktivitas antijamur).

\section{Persiapan Bahan Baku}

Pertama-tama dilakukan pengecilan ukuran bahan pada peko kering teh putih dengan menggunakan grinder. Lalu dilakukan pengayakan dengan rotap tyler ukuran 18 mesh. Pemilihan ukuran mesh dilakukan berdasarkan hasil penelitian Siringo-ringo (2006), yang menyatakan bahwa nilai optimum kadar polifenol teh hijau diperoleh pada ukuran bahan 18 mesh. Setelah bahan diayak akan dihasilkan bubuk teh putih dengan 18 mesh yang siap untuk diekstrak.

\section{Pembuatan Ekstrak Teh Putih}

Pembuatan ekstrak teh putih dilakukan dengan menggunakan metode maserasi bertingkat, dengan perbandingan 1:9, yaitu 100 gram bubuk ditambah $900 \mathrm{ml}$ pelarut. Pelarut yang pertama kali digunakan untuk maserasi adalah n-heksana (non polar). Campuran bubuk dan pelarut diaduk secara manual, setelah 24 jam disaring dengan penyaring vakum untuk memisahkan filtrat dengan ampas, kemudian ampas bubuk di maserasi dengan pelarut selanjutnya yaitu etil asetat (semi polar). Dilakukan perlakuan yang sama seperti maserasi pertama dan selanjutnya ampas dimaserasi dengan pelaru etanol $96 \%$ (polar). Masingmasing filtrat dengan polaritas berbeda diuapkan dengan rotary vacuum evaporator dengan suhu $40^{\circ} \mathrm{C}$ selama \pm 2 jam untuk memisahkan ekstrak dengan pelarut sehingga dihasilkan ekstrak kental. Selanjutnya dilakukan analisis mutu ekstrak dengan pengukur rendemen parsial 
ekstraksi dan rendemen total, pengukuran bobot jenis maserat dan ekstrak dengan metode piknometer, pengujian warna ekstrak dengan chromameter, pengukuran kadar sisa pelarut ekstrak etanol dan pengukuran kadar total polifenol masing-masing ekstrak.

\section{Pengukuran Daya Hambat Ekstrak Teh Putih} (Cappucino dan Sherman, 2001)

Pengukuran daya hambat dilakukan dengan langkah-langkah berikut:

\section{a. Sterilisasi Alat}

Peralatan seperti tabung cawan petri, kertas cakram, pinset, jarum ose dan swab disterilisasi dengan cara menutup peralatan yang akan disterilkan dengan kertas. Sementara untuk tabung reaksi ditutup terlebih dahulu dengan sumbat yang terbuat dari kapas dibalut kain kasa. Kemudian peralatan dimasukan ke dalam oven dan diatur pada suhu $180^{\circ} \mathrm{C}$ selama 120 menit.

\section{b. Pembuatan Media}

Media yang disiapkan adalah media Potato Dextrose Agar (PDA). Pada pembuatan media dilakukan secara aseptis dengan cara bagian ujung alat dipanaskan dan ditutup dengan kapas dan alumunium foil. Masingmasing media yang disterilkan dalam autoklaf dan diatur pada suhu $121{ }^{\circ} \mathrm{C}$ selama 15 menit. Setelah steril media dituang ke dalam tabung reaksi dan dimiringkan.Lalu agar dibiarkan mengeras.

\section{c. Inokulasi Kultur Murni Jamur Pada Media PDA}

Kultur murni Candida albicans diinokulasi pada media padat agar miring yang terbuat dari PDA dan tabung media ditutup dengan kapas.Media tersebut diinkubasi pada suhu $25^{\circ} \mathrm{C}$ selama 48 jam.

\section{d. Pembuatan Larutan Mc Farland 1}

Pembuatan larutan Mc Farland untuk membandingan kekeruhan jamur. Pembuatan media ini dilakukan dengan mencampur 0,1 ml larutan $\mathrm{BaCl}_{2} 1 \%$ (b/v) dan 9,9 ml larutan $\mathrm{H}_{2} \mathrm{SO}_{4}$ $1 \%(\mathrm{v} / \mathrm{v})$. Kemudian bandingkan kekeruhan jamur dengan larutan Mc Farland 1 tersebut dengan menggunakan spektrofotometer dengan panjang gelombang $600 \mathrm{~nm}$.

\section{e. Pengukuran Absorben Kultur Murni}

Dilakukan pengukuran densitas optik (kerapatan) pertumbuhan sel jamur pada panjang gelombang $600 \mathrm{~nm}$ menggunakan spektrofotometer. Hasil dari pengukuran tersebut, dibuat grafik hubungan waktu inkubasi dengan densitas optik dan diperoleh kurva pertumbuhan.

\section{f. Peremajaan Jamur pada Media PDA}

Menuangkan media padat PDA yang telah dipanaskan hingga mencair ke dalam cawan petri $\pm 20 \mathrm{~mL}$ didinginkan sampai suhu \pm $40{ }^{\circ} \mathrm{C}$ hingga memadat, kemudian mencelupkan swab ke dalam suspensi jamur yang telah diukur absorbansinya di torehkan pada permukaan PDA secara zig-zag. Selanjutnya 4 cakram kertas diameter $5 \mathrm{~mm}$ direndam pada masing-masing esktrak dengan pelarut $n$ heksan, etil asetat dan etanol $96 \%$ pada konsentrasi $22 \%, 24 \%, 26 \%$ dan $28 \%$ selama \pm 5 menit, kemudian diletakkan di atas permukaan PDA dengan menggunakan pinset. Media PDA yang sudah tersuspensi jamur di inkubasi dengan suhu $25^{\circ} \mathrm{C}$ selama 24 jam.

\section{g. Perhitungan Diameter Daya Hambat Jamur}

Setelah 24 jam, mengukur luas areal bening yang terbentuk pada cawan petri menggunakan penggaris dan dibandingan dengan kontrol positif ekstrak teh putih dan kontrol negatif negatif yaitu pelarut tanpa pemberian teh putih, yang bertujuan untuk membandingkan kepekaan jamur terhadap ekstrak teh putih dan tanpa teh putih. Diameter daerah bening yang terbentuk dikurangi dengan diameter cakram kertas $(5 \mathrm{~mm})$.

\section{h. Penentuan Konsentrasi Hambat Minimum}

Penentuan KHM pada penelitian ini menggunakan metode difusi disk. KHM ditentukan dengan besar diameter hambat yang dihasilkan oleh disk yang telah direndam dalam ekstrak daun teh putih kemudian ditanam pada agar plate yang telah diswab dengan suspens Candida albicans dan diinkubasi selama 1-2 hari. Perubahan yang diamati pada penelitian ini yaitu terbentuknya daerah hambatan pertumbuhan bakteri yang ada di sekeliling kertas disk berupa ukuran diameter daerah hambat. 


\section{HASIL DAN PEMBAHASAN}

\section{Kadar Air Teh Putih}

Nilai rata-rata kadar air pada teh putih didapat sebesar 6,9\%. Menurut Rancangan Standar Nasional Indonesia (RSNI) (2014), nilai kadar air teh putih maksimal $8 \%$. Hal ini menunjukkan bahwa kadar air yang digunakan untuk menguji aktivitas antijamur sudah memenuhi standar. Nilai kadar air bubuk teh putih didapat sebesar 7,05\% dan peko segar teh putih sebesar $74,47 \%$. Nilai kadar air teh putih lebih kecil dibanding peko segar teh putih. Hal tersebut dikarenakan adanya proses pelayuan dan pengeringan pada saat pengolahan teh putih dilakukan. Nilai kadar air bubuk teh putih kering lebih tinggi dibanding dengan kadar air teh putih. Hal ini diduga karena pada saat pengecilan ukuran bahan dilakukan pada lingkungan yang memiliki kelembaban tinggi sehingga bahan yang higroskopis menyerap udara air dan bau sekelilingnya yang menyebabkan terjadinya perpindahan air dari udara ke bubuk teh putih.

\section{Rendemen}

\section{Rendemen Penggilingan}

Rendemen penggilingan diperoleh berdasarkan bobot teh putih sebelum dilakukan pengecilan ukuran bahan dan bobot hasil pengecilan ukuran bahan dengan grinder. Nilai rendemen penggilingan diperoleh rata-rata sebesar 99,72\%. Hal ini menunjukkan bahwa hanya sekitar $0,28 \%$ bahan yang terbuang saat proses pengecilan ukuran bahan berlangsung. Nilai rendemen penggilingan dapat dilihat pada Tabel 1.

\section{Rendemen Pengayakan}

Rendemen pengayakan diperoleh berdasarkan bobot bubuk teh putih sebelum diayak dengan rotap tyler dengan ayakan 18 mesh dan bobot bubuk teh putih setelah diayak dengan rotap tyler dengan ayakan 18 mesh. Nilai rendemen pengayakan diperoleh sebesar ratarata $99,58 \%$. Nilai ini menunjukkan bahwa sekitar $0,42 \%$ bahan terbuang saat pengayakan. Hal tersebut diduga karena faktor waktu pengayakan dan penimbangan berat bahan yang telah diayak. Nilai rendemen pengayakan dapat dilihat pada Tabel 1.

\section{Rendemen parsial Ekstraksi}

Nilai rendemen parsial ekstraksi tertinggi didapat pada ekstrak teh putih dengan pelarut etanol $96 \%$ sebesar rata-rata $9,42 \%$, sedangkan rendemen terendah didapat pada ekstrak teh putih dengan pelarut $n$-heksana sebesar $0,62 \%$, seperti disajikan di Tabel 1.

Tabel 1. Rendemen Penggilingan

\begin{tabular}{rlc}
\hline \multicolumn{1}{c}{ Rendeman Parsial } & $\begin{array}{c}\text { Rata-rata } \pm \text { SD } \\
\text { (\%) }\end{array}$ \\
\hline 1. & Rendemen & $99,72 \pm 0,20$ \\
& Penggilingan & $99,58 \pm 0,40$ \\
2. & Rendemen & \\
& $\begin{array}{l}\text { Pengayakan } \\
\text { 3. }\end{array}$ & $0,62 \pm 0,04$ \\
& Rendemen ekstraksi \\
n-heksana & \\
4. & Rendemen ekstraksi \\
& etil asetat \\
5. & Rendemen ekstraksi \\
& Etanol 96\% & $1,82 \pm 0,27$ \\
& $9,42 \pm 1,88$ \\
\hline
\end{tabular}

Hal ini diduga karena selama proses maserasi terjadi penguapan pelarut dan masih terdapat pelarut pada ampas sebelum maserasi. Pada tabel 3 dapat dilihat bahwa ekstrak teh putih dengan pelarut $n$-heksana, pelarut etil asetat dan pelarut etanol memiliki rendemen sebesar $0,62 \%, 1,82 \%$ dan 9,42\%. Menurut Harbone (1987), menyatakan bahwa pelarut yang bersifat polar (Etanol 96\%) mampu mengekstrak senyawa alkaloid kuartener, komponen fenolik, karotenoid, tannin, gula, asam amino dan glikosida. Pelarut bersifat semi polar (etil asetat) mampu mengekstrak senyawa fenol, terpenoid, alkaloid, aglikon dan glikosida. Sedangkan senyawa nonpolar mampu mengekstrak senyawa kimia seperti lilin, lemak dan minyak yang mudah menguap. Rendemen total ekstrak teh putih dengan pelarut etanol lebih besar dibandingkan dengan rendemen ekstrak teh putih dengan pelarut etil asetat dan pelarut $n$-heksana. 


\section{Rendemen Total}

Rendemen total diperoleh berdasarkan bobot hasil proses ekstraksi dan bobot bubuk teh putihyang digunakan untuk ekstraksi. Hal ini perlu diperhatikan untuk memperhitungkan kebutuhan bahan guna mendapatkan hasil ekstrak teh putih yang memiliki rendemen tinggi. Nilai rendemen total ekstrak teh putih dengan pelarut n-heksana sebesar $0,62 \%$, pelarut etil asetat sebesar $1,81 \%$ dan pelarut etanol $96 \%$ sebesar $9,32 \%$. Nilai ini disebabkan karena pada proses ekstraksi nilai rendemen ekstrak teh putih dengan pelarut etanol $96 \%$ merupakan yang paling tinggi sehingga berpengaruh terhadap nilai rendemen total yang menyebabkan nilai rendemen total ekstrak teh putih dengan pelarut etanol tertinggi dibanding dengan ekstrak teh putih dengan pelarut lain. Selain itu hal ini diduga karena senyawa aktif yang ditarik oleh pelarut etanol 96\% lebih banyak dibanding dengan pelarut lainnya. Perbandingan nilai rendemen total dapat dilihat pada Gambar 1.

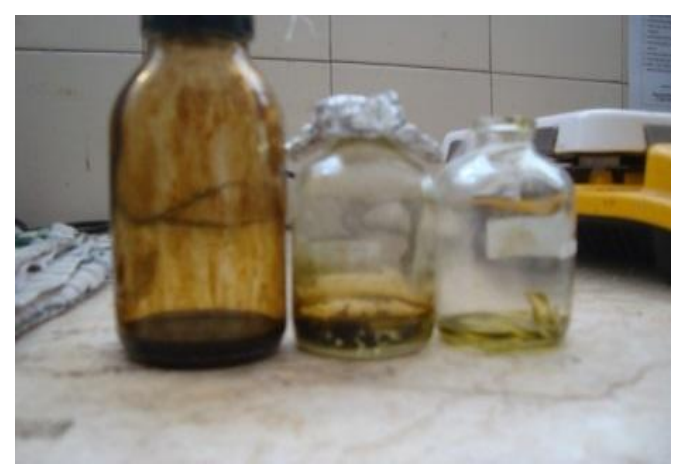

Gambar 1. Ekstrak Teh Putih dengan Pelarut Etanol $96 \%$, etil Asetat dan n-heksana (dari kiri ke kanan)

\section{Bobot Jenis Ekstrak Teh Putih}

Bobot jenis ekstrak teh putih yaitu perbandingan antara densitas ekstrak dengan densitas aquades. Densitas ekstrak menyatakan massa ekstrak teh putih dengan massa pelarut pada suhu dan volume yang sama. Bobot jenis yang dihasilkan pada ekstrak teh putih dengan $n$ heksana, etil asetat dan pelarut etanol $96 \%$ adalah $0,76,1,12$ dan 1,21. Bobot ekstrak teh putih bergantung pada zat-zat yang terkandung dalam ekstrak teh putih tersebut dan terkait dengan kemurnian ekstrak dan kontaminasi (Depkes, 2000).

\section{Kadar Sisa Pelarut}

Sisa pelarut merupakan parameter adanya zat selain air yang ikut hilang dan kadar sisa pelarut menyatakan bahwa ekstrak tidak boleh mengandung pelarut yang digunakan untuk mengekstrak karena jika sisa pelarut yang terkandung mempunyai kadar besar akan dapat mengganggu hasil bila digunakan untuk uji eksperimental hewan dan dapat mengganggu kesehatan jika digunakan dalam sediaan farmasi. Pada penelitian didapat nilai sisa pelarut pada ekstrak teh putih dengan pelarut etanol $96 \%$ sebesar $17,44 \%$.

Menurut Sembiring (2007), batasan sisa pelarut dalam ekstrak adalah sebesar $1,046 \%$. Hal ini berarti bahwa sisa pelarut ekstrak teh putih dengan pelarut etanol $96 \%$ dalam penelitian ini belum memenuhi syarat standar mutu kandungan sisa pelarut, ini dikarenakan kurang sempurnanya proses pemisahan pelarut. Kadar sisa pelarut ini hanya diujikan pada ekstrak teh putih menggunakan pelarut etanol 96\%. Hal ini disebabkan ekstrak teh putih dengan pelarut nheksana dan etil asetat berbentuk padatan dan diasumsikan tidak memiliki kandungan sisa pelarut.

\section{Warna Ekstrak Teh Putih}

Warna ekstrak teh putih, bubuk teh putih dan peko kering teh putih diukur dengan menggunakan chroma meter. Parameter yang dihitung pada pengukuran warna adalah nilai Hue dan Chroma. Nilai Hue ditujukan untuk mewakili panjang gelombang dominan yang menyatakan kisaran warna pada suatu bahan pangan. Rata-rata nilai Hue yang didapat pada ekstrak dengan pelarut n-heksana, etil asetat dan etanol $96 \%$ sebesar 116,6, 134,14 dan 142,12,. Nilai Hue tertinggi didapat pada ekstrak teh putih dengan pelarut etanol $96 \%$ sebesar 142,12 , sedangkan nilai Hue terendah didapat pada ekstrak teh putih dengan pelarut $\mathrm{n}$-heksana berkisar 116,6 .

Menurut Winarno (2004), pada dasarnya warna bahan pangan terdiri dari warna merah, kuning, hijau, dan biru, sehingga warna yang dihasilkan merupakan hasil dari kombinasi warna dasar tersebut. Berdasarkan hasil pengukuran yang didapat, nilai Hue ekstrak teh putih dengan pelarut n-heksana menunjukkan warna kuning (yellow). 
Sedangkan nilai Hue ekstrak teh putih dengan pelarut etanol $96 \%$ dan etil asetat menunjukkan warna kuning kehijauan (yellow green). Astawan dan Andre (2008), menyatakan bahwa warna kuning dari suatu bahan pangan berasal dari senyawa flavonoid yang dihasilkan. Warna Hue ekstrak teh putih ini diduga berasal dari senyawa flavonoid.

Menurut Winarno (2004), nilai chroma menunjukkan intensitas warna yang dihasilkan. Nilai chroma yang rendah menandakan bahwa warna bahan yang diperoleh itu lemah atau pudar, sebaliknya nilai chroma yang tinggi maka warna yang diperoleh sangat kuat sehingga terlihat sangat mencolok (Supriadi, 2013). Nilai chroma tertinggi didapat pada ekstrak teh putih dengan pelarut n-heksana sedangkan nilai chroma terendah didapat pada ekstrak teh putih dengan pelarut etanol.Nilai chroma dapat dilihat pada Tabel 2.

Tabel 2. Nilai Chroma, Hue, dan Chromatisitas

\begin{tabular}{cccc}
\hline Bahan & $\begin{array}{c}\text { Nilai } \\
\text { Hue }\left({ }^{\circ}\right)\end{array}$ & $\begin{array}{c}\text { Nilai } \\
\text { Chroma }\end{array}$ & Chromatisitas \\
\hline $\begin{array}{c}\text { Ekstrakn- } \\
\text { Heksana }\end{array}$ & 116,6 & 9,41 & Yellow \\
$\begin{array}{c}\text { Ekstrak Etil } \\
\text { Asetat }\end{array}$ & 134,14 & 7,84 & Yellow Green \\
$\begin{array}{c}\text { Ekstrak } \\
\text { Etanol 96\% }\end{array}$ & 142,12 & 6,24 & Yellow Green \\
\hline
\end{tabular}

\section{Kandungan Polifenol Ekstrak Teh Putih}

Pengukuran kadar polifenol dilakukan pada ekstrak teh putih dengan pelarut etanol $96 \%$, etil asetat dan $\mathrm{n}$-heksana. Hasil pengukuran kadar polifenol yaitu n-heksana sebesar $22,04 \%$, etil asetat sebesar 57,54\%, etanol $96 \%$ sebesar $59,32 \%$. Nilai kandungan polifenol tertinggi didapat pada ekstrak teh putih dengan pelarut etanol $96 \%$ yaitu sebesar 59,32\%. Hal tersebut dikarenakan setiap jenis pelarut memiliki tingkat polaritas yang berbeda. Etanol $96 \%$ merupakan salah satu jenis pelarut yang memiliki tingkat polaritas yang lebih tinggi dibanding dengan jenis pelarut etil asetat dan $n$-heksana.Selain itu, etanol 96\% juga merupakan pelarut universal yang dapat menarik senyawa aktif dari golongan semi polar dan nonpolar.

\section{Aktivitas Antijamur}

Kekeruhan suspensi jamur yang dihasilkan sebesar 0,214.Nilai ini mendekati nilai kekeruhan $m c$ farland 1 yaitu 0,223. Hasil penelitian memperlihatkan bahwa ekstrak teh putih dapat menghambat pertumbuhan jamur Candida albicans. Kepekaan jamur terhadap ekstrak teh putih ditentukan oleh diameter daerah bening yang terbentuk, semakin besar diameter area bening yang terbentuk maka semakin terhambat pertumbuhan jamur Candida albicans. Kepekaan jamur terhadap ekstrak teh putih diduga karena senyawa yang terdapat di ekstrak teh putih bersifat fungistatik. Menurut Putri (2013), Mekanisme penghambatan pertumbuhan fungi (jamur) adalah dengan cara menghambat kerja enzim tertentu yang mengakibatkan terganggunya metabolisme sel fungi, sehingga proses pemanjangan hifa (misellium) fungi menjadi terhambat. Jika pertumbuhan sel fungi yang ditandai dengan pemanjangan hifa (misellia) terhambat, maka fragmentasi hifa pun menjadi terganggu sehingga dapat dikatakan bahwa sel fungi tidak dapat berkembangbiak. Hifa atau miselium yang tidak dapat mengalami fragmentasi disebabkan oleh rusaknya jaringan hifa. Rusaknya jaringan hifa mengakibatkan sel fungi pada saat bersamaan menjadi peka dan rentan terhadap perubahan lingkungan, sehingga sel fungi mudah mati.

Berdasarkan hasil pengujian, konsentrasi terkecil yang diujikan yaitu $22 \%(\mathrm{~b} / \mathrm{v}$ ) ditemukan diameter daya hambat sebesar $11,50 \mathrm{~mm}$. Menurut Suryawiria (1978), kemampuan suatu senyawa dalam menghambat pertumbuhan jamur dikatakan kuat pada nilai diameter daya hambat sebesar 10-20 mm. Konsentrasi hambat minimum adalah konsentrasi terendah suatu senyawa dalam menghambat pertumbuhan jamur secara kuat.

Hasil pengujian menunjukkan bahwa konsentrasi hambat minimum pada ekstrak teh putih dengan pelarut etanol ditemukan pada konsentrasi $22 \%(\mathrm{~b} / \mathrm{v})$. Pada pelarut etil asetat, konsentrasi uji terkecil yang menghasilkan diameter daya hambat $>10 \mathrm{~mm}$, ditemukan pada konsentrasi $28 \%$ (b/v) dengan rata-rata sebesar $11,33 \mathrm{~mm}$. Hal ini menunjukkan bahwa pada pelarut etil asetat, konsentrasi hambat minimum 
ditemukan pada konsentrasi $28 \%$ (b/v). Pada pelarut $\mathrm{n}$-heksana, tidak ditemukan diameter hambat yang bernilai $>10 \mathrm{~mm}$. Hal ini menunjukkan bahwa ekstrak teh putih dengan pelarut $\mathrm{n}$-heksana pada kisaran konsentrasi 22\%$28 \%(\mathrm{~b} / \mathrm{v})$ tidak ditemukan konsentrasi hambat minimum. Pada pelarut $n$-heksana tidak ditemukan diameter daya hambat. Hal ini diduga dikarenakan ekstrak teh putih dengan pelarut $n$-heksana tidak berdifusi dengan baik ke dalam paper disk. Hasil pengujian konsentrasi hambat minimum ekstrak teh putih dengan pelarut $\mathrm{n}$-heksana, etil asetat dan etanol terhadap Candida albicans dapat dilihat pada Gambar 2.

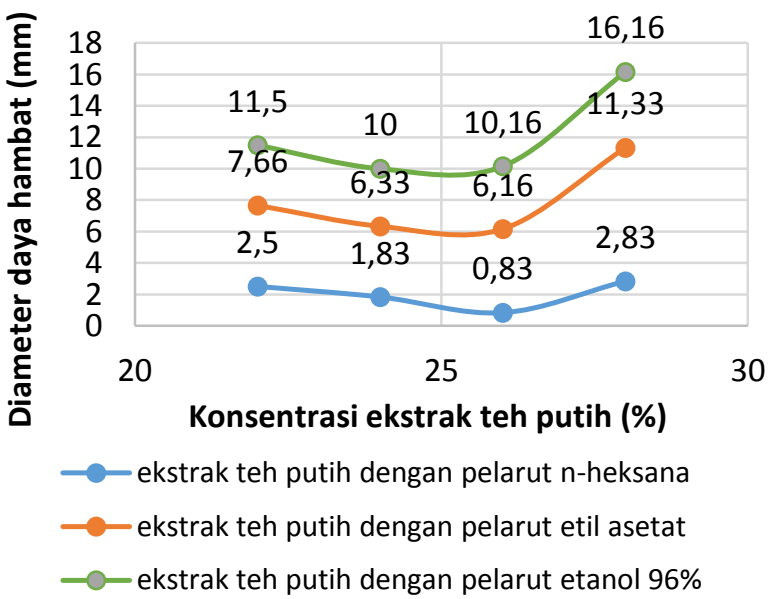

Gambar 2.Konsentrasi Hambat Minimum Ekstrak Teh Putih

Besarnya nilai konsentrasi tidak berbanding lurus dengan diameter daya hambat yang dihasilkan.Hal ini diduga karena komposisi serat paper disk yang tidak seragam, sehingga diameter area bening yang terbentuk tidak merata. Selain itu faktor yang sulit dihindari lainnya adalah ketebalan medium agar yang tidak seragam, karena pada saat penuangan media agar ke setiap cawan petri tidak persis sama banyaknya, sehingga ketebalannya berbeda. Waktu inkubasi yang digunakan bukan merupakan waktu optimal untuk pertumbuhan normal jamur uji, yaitu 6 hari.Waktu inkubasi yang digunakan adalah 1 hari, sebab diperkirakan apabila melewati batas waktu tersebut areal bening yang terbentuk tertutupi oleh jamur.

\section{KESIMPULAN DAN SARAN}

\section{Kesimpulan}

Aktivitas antijamur ekstrak teh putih dengan pelarut etanol $96 \%$ adalah yang tertinggi. Hal tersebut dapat dilihat dari ditemukannya areal bening terbesar pada konsentrasi $28 \%$ sebesar rata-rata $16,6 \mathrm{~mm}$ yang termasuk dalam kategori kuat. Pada pelarut etil asetat ditemukan aktivitas antijamur tertinggi pada konsentrasi $28 \%$ yaitu rata-rata sebesar $11,33 \mathrm{~mm}$. Sedangkan pada pelarut $n$-heksana ditemukan aktivitas antijamur tertinggi pada konsentrasi $28 \%$ yaitu rata-rata sebesar 2,83 $\mathrm{mm}$. Adapun parameter penunjang seperti kadar polifenol dalam ekstrak menjadi acuan banyaknya senyawa aktif berupa polifenol yang berkhasiat sebagai zat antijamur. Kadar polifenol tertinggi terdapat dalam ekstrak teh putih dengan pelarut etanol $96 \%$ yaitu sebesar $59,32 \%$.

Konsentrasi hambat minimum yang ditemukan di range konsentrasi 22\%-28\% (b/v) pada ekstrak teh putih dengan pelarut etanol $96 \%$ adalah $22 \%(\mathrm{~b} / \mathrm{v})$, pada pelarut etil asetat adalah $28 \%(\mathrm{~b} / \mathrm{v})$ sedangkan pada n-heksana tidak ditemukan konsentrasi hambat minimum.

\section{Saran}

Perlu dilakukan penelitian lebih lanjut tentang karakteristik teh putih dan ekstrak teh putih dengan menggunakan jenis yang ekstraksi lain serta perlu dilakukan pengujian aktivitas antijamur ekstrak teh putih dengan metode selain difusi cakram.

\section{DAFTAR PUSTAKA}

Astawan, M. dan Andre, L.K. 2008.Khasiat Warna Warni Makanan. Jakarta:Gramedia Pustaka Utama

Balai Penelitian Tanaman Industri dan Penyegar (Balittri).2013. Teh Putih yang Langka dan Mahal. Tersedia pada : :http://balittri.litbang.deptan.go.id/index.ph $\mathrm{p} /$ component/content/article/49infotekno/177-teh-putih yanglangka-danmahal (diakses pada tanggal 20 Februari 2015 pukul 18.00 WIB). 
Bassoon, Miranda dan Wyk, Van. 1996. The effect of Areca nut on salivary and selected oral microorganism. J Int Drnt. (4): 350-6.

Cappucino, J.G. and Sherman, N. 2001.Microbiology: A Laboratory Manual. $2^{\text {nd }} \quad$ Edition.The Benjamin Cummings Publishing Company.Rockland Community College.State University of New York.

Chu, D. C., and Juneja.1997. General Chemical Composition of Green tea and Its Infusion.Chemistry and Applications of Green Tea. CRC Press LLC. USA

Darwis , D. 2000. Teknik Dasar Laboratorium Dalam Penelitian Senyawa Bahan Alam Hayati. [Workshop Pengembangan Sumber Daya Manusia Dalam Bidan Kimia Organik Bahan Alam Hayati.]FMIPA Universitas Andalas. Padang.

Departemen Kesehatan Republik Indonesia. 2000. Parameter Standar Umum Ekstrak Tumbuhan Obat. Direktorat Pengawasan Obat dan Makanan. Depkes RI. Jakarta

Harborne, J. B. 1987 Metode Fitokimia. Bandung : Institut Teknologi Bandung.

Hartoyo, A .2003, Teh dan Khasiatnya bagi Kesehatan.Kanisius.Yogyakarta.

Khopkar, S. M. 2003. Konsep Dasar Kimia Analitik. terjemahan A. Saptorahardjo. UI Press. Jakarta.

Kurniawan, J.A. 2009. Uji Aktivitas Antijamur Ekstrak Rimpang Binahong (Anredera cordifolia (Tenore) Steen) terhadap Jamur Candida albicans serta Skrining Fitokimianya. [Skripsi]. Fakultas Farmasi Universitas Muhammadiyah Surakarta.

Pastore, R. 2005. Green \& White Tea Max A: A Closer Look at the Benefits of Green and White Tea. White Paper.p 16.
Pelczar, Jr. M.J. dan Chan, E.C.S. 2005. Dasar-Dasar Mikrobiologi Jilid 2. Alih bahasa: Ratna Sri Hadioetomo dkk. Jakarta: UI Press.

Prasidha.2013. Efektivitas Ekstrak Daun Teh Hijau (Camellia sinensis) dalam Menghambat Pertumbuhan Candida albicans secara in vitro.[Skripsi]. Fakultas Kedokteran Universitas Brawijaya.

Putri, A. U. 2013. Uji Potensi Antifungi Ekstrak Berbagai Jenis Lamun terhadap Fungi Candida albicans.[Skripsi]. Universitas Hasanudin. Makasar.

RSNI. 2014. Rancangan Standar Nasional Indonesia untuk Teh Putih. Badan Standar Nasional Indonesia.

Siringo-ringo, M. P., 2006, Optimasi Ekstraksi Polifenol Teh Hijau Berdasarkan Ukuran Butir, Nisbah Bahan Baku-Pelarut dan Waktu [Skripsi], Institut Pertanian Bogor. Bogor.

Sembiring, B. Br., 2007, Status Teknologi Pasca Panen Sambiloto (Andrographis paniculata Nees), Perkembangan Teknologi Tanaman Rempah dan Obat, Balai Penelitian Tanaman Obat dan Aromatik, 19 (2), 134-144.

Supriadi, A. 2013.Pengaruh Penambahan Tinta Cumi-Cumi (Loligo sp) terhadap Kualitas Nutrisi dan Penerimaan Sensoris Mi Basah. [Skripsi]. Universitas Sriwijaya. Palembang

Suryawiria, U. 1978.Mikroba Lingkungan.Ed ke2.Institut Teknologi Bandung. Bandung

Syah, A. N. A. 2006. Teh Hijau dan Kesehatan, Taklukan Penyakit Dengan Teh Hijau. Jakarta: Agromedia Pustaka

Winarno, F. G. 2004. Kimia Pangan dan Gizi. PT. Gramedia. Jakarta. 